\section{Farbmessung von Textilien, Kunststoffen und Lackbeschichtungen}

$D^{\prime}$ ie Firma X-Rite präsentiertmit dem RM200QC ein preisgünstiges Hand-Spektralkolorimeter zur Ermittlung von Farbabweichungen. Das Gerät eignet sich insbesondere für die Textil- und Chemieindustrie oder die Verarbeitung von Lacken und Kunststoffformteilen. Es ermöglicht einen

Farbvergleich von Laborproben oder Produktionsteilen

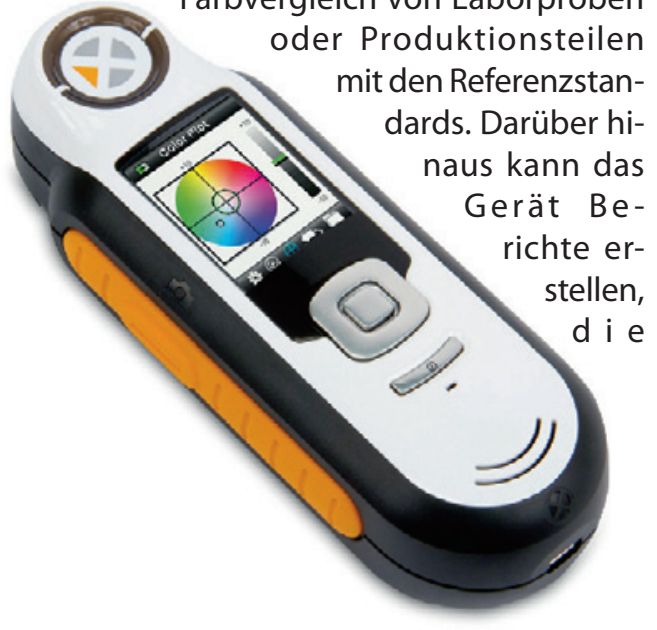

\section{Kolbenmembranpumpe} mit hohem Druck

Mit der neuen KolbenmembranMumpe Hydra-Cell G35 von Wanner können Medien jetzt mit einem Druck von bis zu 98 bar bei $500 \mathrm{U} / \mathrm{min}$ gepumpt werden. Das entspricht einer Steigerung um 18,5 Prozent gegenüber der Standardausführung mit 83 bar. Zwar belastet der höhere Druck das Lagersystem stärker. Aufgrund der geringen Geschwindigkeit wird die Lebensdauer der Anlage dennoch nicht verkürzt. Wie der Anbieter der Pumpe, die Firma Verder, mitteilt, erreicht die neue Pumpe wie ihre Vorgänger auch eine Ef-

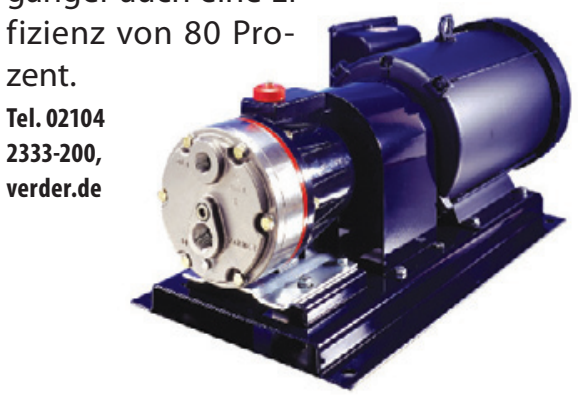

\section{Handliche}

an die weiteren Partner der Lieferketten übermittelt werden können. Neben der Ermittlung von Farbdifferenzen zwischen Proben und Standards kann das Gerät auch Opazität und Grauskala bewerten. Darüber hinaus zeigt es an, wie sich das Aussehen der Farbe unter den Lichtarten D65 (Tageslicht) und A (Wohnraumbeleuchtung mit Wolframdraht-Glühlampen) ändern kann. Das Messgerät bietet sich vor allem für Unternehmen an, die die Farbkonsistenz kontrollieren, indem sie eintreffende Werkstoffe oder Fertigprodukte mit Farbfeldern, Farbfächern oder Mustern vergleichen.

Tel. 0610279 570, www.xrite.com

\section{Ultraschallgeräte für die zerstörungsfreie Werkstoffprüfung}

Für die zerstörungsfreie Werkstoffprübietet die Firma Elcometer jetzt diverse handliche und vielseitig verwendbare UItraschallmessgeräte an. Mit Ultraschallmessgeräten können Qualitätsmängel der Wanddicke, der Beschichtung und der Oberflächen (Korrosion) und Risse rechtzeitig erkannt werden. Die Ultraschallprüfung kann an fast allen Werkstoffen vorgenommen werden. Für verschiedene Einsatzgebiete stehen verschiedene Ultraschallmessgeräte der NDT-Serie mit den dazugehörigen Messköpfen zur Verfügung. Diese sind bis zu einer Temperatur von $482^{\circ} \mathrm{C}$ einsetzbar. Die Geräte sind ergonomisch geformt, haben versiegelte Metallgehäuse sowie wasser- und staubdichte Membrantastenfelder. Die NDT-Serie bietet ein breites Spektrum an Messmodi, wobei die Anzahl der Modi je nach Modell variiert. Des Weiteren wird ein umfassendes Sortiment von Zweielement-Messköpfen für die Dickenmessung in Verbindung mit den Korrosions-, Geschwindigkeits- und Materialfehlerprüfgeräten angeboten. Tel. 07361 52806, www.elcometer.de
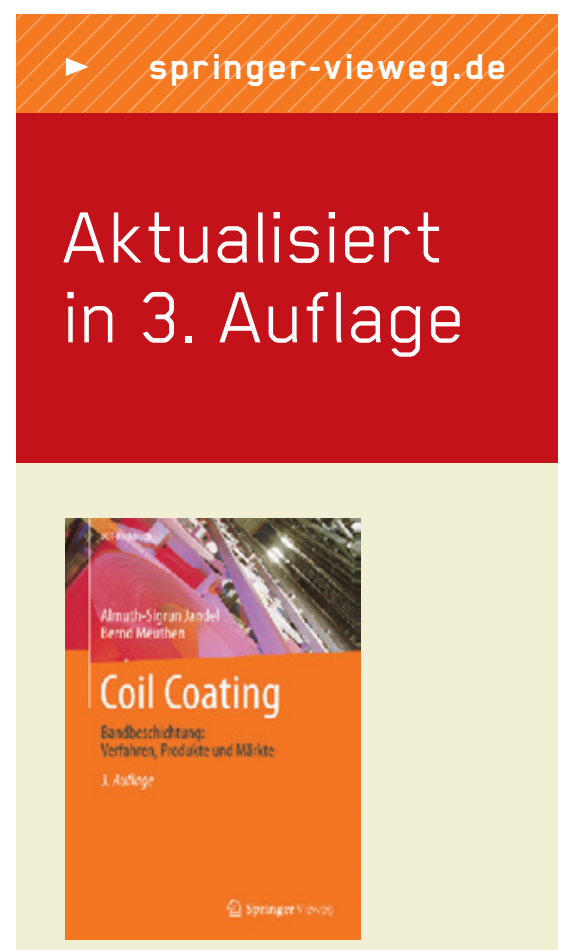

Meuthen, Bernd I

Jandel, Almuth-Sigrun

Coil Coating

Bandbeschichtung: Verfahren, Produkte und Märkte

3. Aufl. 2013. X, 368 S. mit 191 Abb. u. 38 Tab. Geb.

ISBN 978-3-8348-1971-0

- $€(D) 64,95$

Das Buch bietet einen systematischen und anschaulichen Einblick in Beschichtungssysteme, Beschichtungsprozesse und den Einsatz von bandbeschichteten Aluminium- und Stahlblechen in der metallverarbeitenden, in der Bau-, Hausgeräte- und Automobilindustrie. Wichtige Aspekte für die Verarbeitung und zum Umweltschutz geben zuverlässige Informationen für die Praxis. Mit der dritten aktualisierten Auflage wird den aktuellen Entwicklungen in der Bandbeschichtung Rechnung getragen. Neue Trends und Technologien werden aufgezeigt und zudem wurden Daten und Normen auf den aktuellen Stand gebracht.

Einfach bestellen: SpringerDE-service@springer.com Telefon $+49(0) 6221 / 345-4301$ 